\title{
Vorwort zur neunten Auflage.
}

Als vor einiger Zeit von dem Herrn Verleger die Aufforderung an mich erging, eine nene Auflage dieses Buches vorzubereiten, kam ich nach reillicher Eeberlegung zu der Leberzeugung, dass ich ausser Stande sei, cine solche Arbeit so gründlich durchzuführen, wie ich es früher mit Freuden gethan hatte. I)ie Praxis und das sociale I,eben neben meiner I,ehrthätigkeit haben im Lauf der letzten Decennien meine Arbeitskraft so absorbirt, dass ich den Fortschritten der medicinischen Hilfswissenschaften nicht mehr so folgen konnte, wie es sein soll, wenn man sich anschickt, die Resultate rler Albeiten neuer Generationen für neue Generationen zu cinem übersichtlichen, kritisch gesichteten Ganzen zu verarbeiten. So schwer es mir auch wurde, ich musste mich entschliessen, auf eine eigene neue Bearbeitung dicser Vorlesungen zu verzichten. - Zu meiner grossen Freude hat nun Herr Professor Dr. Alexander von Winiwarter diese Arbeit iibernommen und so glücklich und gediegen durchgeführt, dass das Buch wieder für einige Zeit den Studirenden und Aerzten als Leitfaden auf dem grossen Gebiete der allgemeinen chirurgischen Pathologie und Therapie dienen kann. - Diese Aufgabe war cine ganz besonders schwierige, weil dies Buch, so ganz aus meiner Individualität hervorgegangen, und im ersten Entwurfe schon vor 20 Jahren ausgearbeitet, durchweg einen vorwiegend subjectiven Stempel trägt. Herr Professor von Winiwarter hat diesen meinen subjectiven Standpunkt pietätvoll gewahrt; ich wünsche indess und autorisire ihn ausdrücklich dazu, dass er bei folgenden Auflagen das ganze Buch mehr und mehr nach seinen Anschauungen und denjenigen der jüngeren Chirurgen-Generation umformt; nur dann wird es sich auch fernerhin lebensfähig erweisen. 
Mit diesen Zeilen nehme ich als chirurgischer Schriftsteller Abschied von einem Leserkreis, der mir seine warmen Sympathieen so oft in freundlichster Weise dargethan hat. Ich darf mit Stolz sagen, dass mein Streben, bei der studirenden Jugend für die herrliche Kunst und Wissenschaft der Chirurgie Freude und Theilnahme zu erwecken, glänzend belohnt worden ist. Tausend Dank Allen, die mich in diesem Streben unterstützt haben!

Wien im Januar 1880.

Th. Billroth.

\section{Vorwort zur zwölften Auflage.}

Als ich im Jahre 1880 die neuen Auflagen dieser Vorlesungen an meinen Schüler und Freund, Herrn Professor Dr. Alexander von Winiwarter ïbergab, habe ich den Wuusch ausgesprochen, dass der Herausgeber bei den folgenden Auflagen das ganze Buch mehr und mehr nach seinen Anschauungen und denjenigen der jüngeren Chirurgen-Generation umformen möge, weil es sich nur dadurch auch fernerhin lebenskräftig und nützlich erweisen kann. Nachdem dies in trefflichster Weise geschehen und immer neue Auflagen nöthig wurden, ist naturgemäss so viel von der Autorschaft und dem Erfolge auf Herrn Professor von Winiwarter übergegangen, dass er nicht mehr als Herausgeber, sondern als Mitarbeiter zu diesem Buche gehört. Ich habe gewünscht, dass dies auch auf dem Titel des Buches ausgedrückt werde, wie es bei dieser zwölften Auflage geschehen ist. Möge unsre gemeinsame Arbeit auch fernerhin die studirende Jugend anregen, ihr die Methoden und Bahnen des Fortschrittes der Wissenschaft zeigen, und ihr für die Praxis ein treuer Rathgeber sein!

Wien, den 12. Mai 1885.

Th. Billroth. 